\title{
A literature review on maintenance priority - conceptual framework and directions
}

\author{
Alan Chong Kim Wing ${ }^{1, a}$, Abdul Hakim bin Mohammed ${ }^{2}$ and Mat Naim bin Abdullah ${ }^{3}$ \\ 1,2,3 Department of Real Estate, Faculty of Geoinformation and Real Estate, University Teknologi Malaysia, Johor Bahru, Malaysia
}

\begin{abstract}
Proper maintenance prioritization enables organization to ensure their maintenance performance remains in the acceptable level. This paper aims to examine the relevant literature related to maintenance priority. Based on this paper, a conceptual framework and future research directions are presented. A database of 184 publications published during 1990 to 2015 was reviewed for the purpose of this paper. The literature review presented the factors used in maintenance priority, methods for priority setting, and the trend of maintenance priority. A discussion was carried out on the maintenance priority based on organisation goal and balancing maintenance priority. Based on this literature review, a conceptual framework, which presents the facets of factors and methods considered in maintenance priority setting is offered. The understanding of factors and methods considered in maintenance priority setting can aid maintenance managers in maintenance planning and ensure maintenance performance of the assets remains compliant with the needs of the organization.
\end{abstract}

\section{Introduction}

Maintenance is crucial in keeping building, infrastructure, and equipment in the best form for normal use [1]. Maintenance is not limited to a certain type of building or location. Regardless of the construction cost of the buildings, they still carries maintenance consequences [2]. In the past, maintenance was viewed as necessary evil because the cost it incurs [3]. Most organisations treat maintenance as a cost burden and demonstrates reluctance to spend in order to preserve the condition of their assets [4]. This reluctance causes a drop in performance and prevents optimum operating capacity.

Maintenance is a costly element in a building's life cycle. Approximately $75 \%$ of the total expenditure on life cycle cost of a building is due to maintenance [5]. After construction is completed, more than $90 \%$ of the life cycle of building projects requires maintenance [6]. This further proves that maintenance is a critical element in any organisation and it carries dire consequences if ignored. Inadequate maintenance of facilities is a poor economic decision because it generates maintenance backlog which must be addressed in the future [7].

\section{Background}

[8] stated that "priority management is the allocation of resources, or the expression of preference, to specific order or order groupings (whether supplies, production, or customer orders), in response to current pressures on operational productivity and/or customer service, with the aim of relieving those pressures while at the same time

\footnotetext{
${ }^{\mathrm{a}}$ Corresponding author: alanchong19882003@gmail.com
}

promoting, or minimizing the deleterious impact upon, the wider economic and strategic goals of the company". Instability requires rebalancing of resources and tradeoffs. In [8], it is stated that instability causes prioritizing actions. Instability refers to changes in volume, variation and variety.

Demand for maintenance actions is always greater than the resources available [9]. More than often, the budget approved is less than needed [10]. This often leads to budgetary cuts. One of the most common area to suffer budgetary cuts is maintenance. Deferments of maintenance works are carried out in order to reduce cost or give way to areas that the organisation deems to be more important. This solution is not cost-effective and maybe not be the best practice to achieve value for money [11]. However, the reality is that the allocation for maintenance will never match the required amount and thus prioritization is practiced. Prioritization of maintenance is a way to tackle the problem of lack in maintenance allocation [12]. Changes imposed on the management of infrastructure in Scotland caused managers to struggle in prioritizing management and maintenance of bridges as there is limited funding [13]. It is common for property managers to face difficulties in setting maintenance priorities. [14]. Facility managers experience increasing pressure to prioritize the direction of limited resources to address maintenance and capital renewal needs. The results of bad prioritization of the direction of resources and capital appropriately include unscheduled facility maintenance, system unavailability, and additional expense to repair or replace failed components or systems due to short/emergency notice 
procurements [15]. In order to decide which maintenance work to prioritize and the consequences of each prioritization, it requires the consideration of multiple factors and thorough understanding of the business [16].

The study attempts to shed some light on important factors and methods used in maintenance priority. For this purpose, the relevant literature is examined, classified and analyzed.

\section{Methodology}

An exhaustive search of literatures related to maintenance priority and maintenance performance was conducted. The database reviewed were: Emerald, ScienceDirect, Scopus Taylor and Francis, JSTOR, and SpringerLink. Related books and search engines were reviewed as well

In total, 184 literature were reviewed. The reviewed literature consisted of models, framework, techniques and factors. The period of the review is from 1990 to 2015. Literature with redundancy and unsuitable for this paper were excluded. Figure 1 shows the publication related to maintenance priority distributed over the period of 19902015.



Figure 1. Publication over period of 1990-2015

A total of 70 journals were reviewed. 26 journals which have more than 2 publication related to maintenance priority is shown in Figure 2. The top six journals are Journal of Quality in Maintenance Engineering, Facilities, Journal of Facilities Management, Structural Survey, Construction Management and Economics, and Reliability Engineering and System Safety. Journal of Quality in Maintenance Engineering is where most articles related to maintenance priority are published. 13.5 percent of the total search comes from this journal.

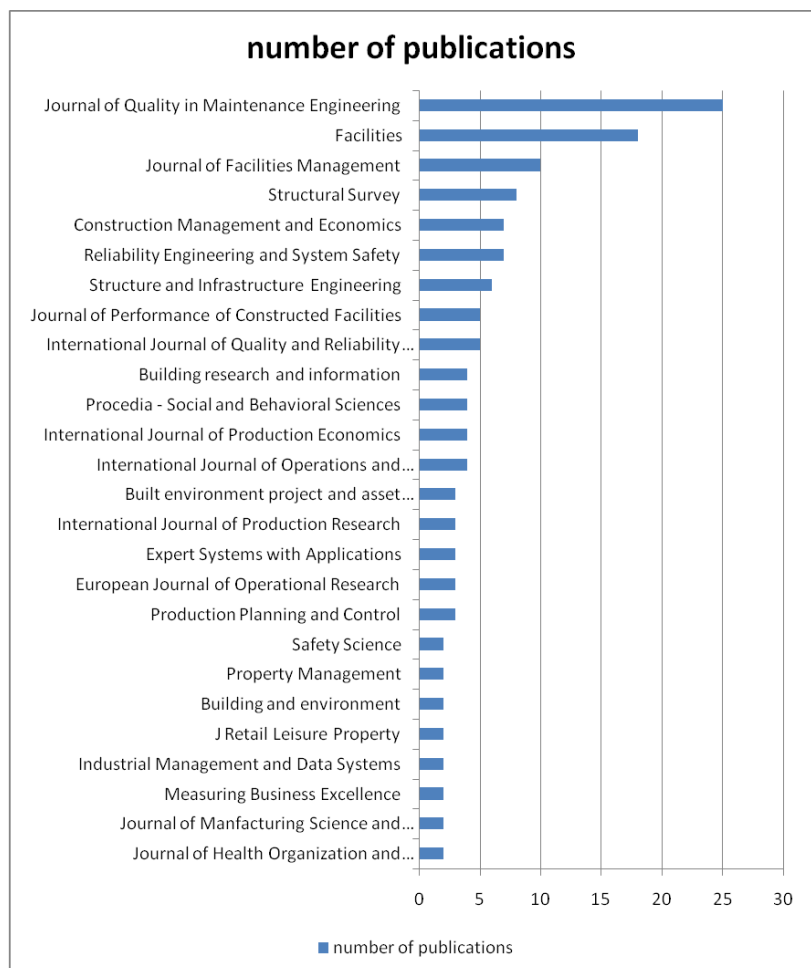

Figure 2. Publication in journals

\section{Results}

Through detailed and systematic content analysis of the publications, a total of 62 presented framework/models and measurements were reviewed. Analytic Hierarchy Process (AHP) based measurement recorded the highest followed by priority criterion, matrix based measurement, framework and Failure Mode and Effect Analysis (FMEA) based measurement. Some of the least used methods are; simple comparison, criticality index, additive ration assessment (ARAS), fuzzy group Analytic Network Process (ANP), cost-based criticality, Roue's formula, benchmarking, Artificial Neural Network (ANN), probabilistic risk assessment, comparative risk analysis, critical failure analysis, and priority cost FMECA. The AHP group has a few variations which include Goal Programming (GP), Bayesian Tools and decision rules. FMEA based measurement includes Risk Probability Number and Fuzzy sets. The variation of matrix is based on importance and performance matrix, priority matrix, priority category matrix, hybrid structural interaction matrix and risk priority matrix.

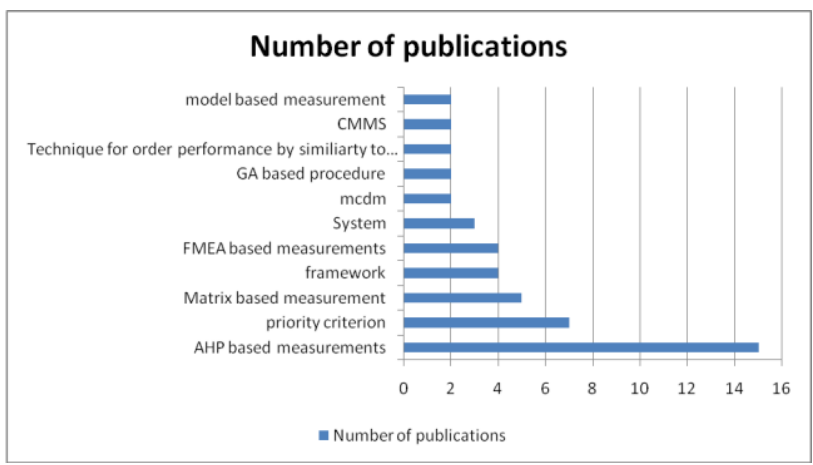

Figure 3. Priority-setting methods 
66 literature contain the factor used in maintenance priority setting as shown in Figure 4 . The most common indicator used is condition assessment and maintenance cost (direct and indirect) followed by occurrence, severity, importance of usage and safety. The least use factors are urgency, labour, availability, satisfaction, complaints, remaining life cycle, aesthetics, economic motivation, scheduling, comfortable use, facilities, economic performance, managerial problems, damage value, type of material, historical data, pressure from maintenance, ability to response, reliability, long term effect, objectives, applicability, stakeholders, public relation, information system, work measurement and incentives, repairability, social and cultural problems, bottlenecks and indoor environmental quality.

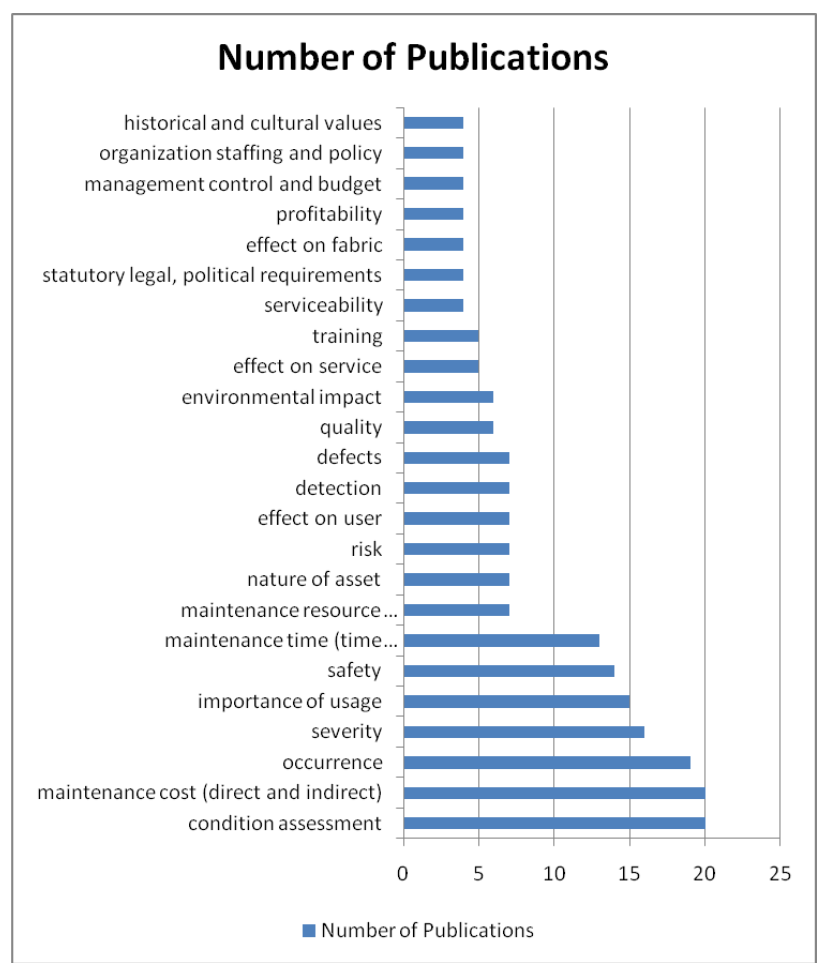

Figure 4. Factors used in setting maintenance priority

An attempt to categorize these factors has been carried out as shown in Table 1. The factors is then categorized into 4 different major categories: Technical, Financial, Social, Political.

Technical factor refers to the performance measurement of an asset [17]. Indicators in form of figures are used to monitor the performance of certain process, systems, equipment and components [18]. [19] included condition, age, life span, energy rating and complexity under the technical factor for planned maintenance prioritization. Physical assessment such as building age and building condition is one of the dominant variables in maintenance planning [20]. In a study to prioritize maintenance, the physical condition of the defective element was examined together with its possibility of breaking down [21]. Elements in critical condition would occupy higher priorities than those in fair condition. Historical maintenance data can also be used as inputs in measuring performance as well [22, 23].
Financial usually refers to budget and cost. There is a need to have a balance between the both for a maintenance plan to succeed. Budget is a strong determinant in any maintenance planning. [20, 24, 25]. A lack of budget can cause shift in priorities and changes in maintenance planning [20]. A sufficient budget is required to procure the needed resources. Resources can refer to equipment, labour, time and cost [26]. The lack of resources causes inability to execute maintenance work. These resources usually translate into monetary needs and can only be satisfied by sufficient budget. In other words, it is the cost required to carry out maintenance. In a study by [24] stated cost of maintenance can be divided into cost of maintenance, cost of recurrent problems, cost of non-functioning, cost of temporary access, and cost of non-maintenance. According to [27], cost can be categorized into direct cost and indirect cost. Direct costs are related to labour costs, spare parts, and other direct cost involved with maintenance works while indirect costs are related to cost from recovering the lost of production and quality insufficiency. While direct cost such as cost of maintenance (manpower and spare parts) are more commonly known, indirect cost such as cost of nonfunctioning for essential services to the organization is difficult to be measured.

According to [19], the social factors in prioritizing maintenance covers health and safety, building usage, security and building status. In most maintenance management, safety and health requirements are considered as command factors in decision making for managing asset [20]. Safety are closely related to risk. Risk affects the degree of risk of life, physical integrity, health and comfort [28]. The common way to measure risk is through likelihood and consequences [29]. For local authorities in Britain, maintenance priorities related to legal requirements, contracting requirements and safety and health of building occupants and users are considered as the top priority [9]. Legal requirements include legislations, statutory and contracting requirements [19]. Other than that, the other effects on users such as customer satisfaction should not be neglected as they are the main users of the building. [30] concluded that the maintenance works of university buildings need to be prioritized based on perspective of users.

In the political category, it refers to the stakeholders of the organisation. The categories of stakeholders include end-users, managers and others involved in the organizational process [31]. The requests of client or owner of the building must be fulfilled. The requests revolves on the organization strategies, corporate image and identity [20]. Poor communication with the client would influence maintenance performance. As infrastructure assets have multiple functions, there are multiple actors (users, political bodies, private sector) involved or affected by the decisions made on asset management [32]. When defining objectives and planning for asset management, their expectations need to be included and managed even 
Table 1. Matrix table for maintenance priority factors

\begin{tabular}{|c|c|c|c|c|c|c|c|c|c|c|c|c|c|c|c|c|c|c|c|c|}
\hline References Factors & $\begin{array}{l}\text { 哥 } \\
\text { 害 }\end{array}$ & 慈 & 형 & 홒 & 篇 & 危 & 窟 & 首 & 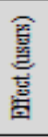 & 总总 & 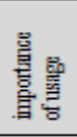 & 疍 & 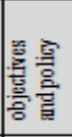 & $\begin{array}{l}\text { 暿 } \\
\text { है }\end{array}$ & 总 & 骂 & 鼻 & 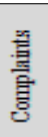 & 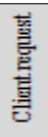 & 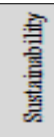 \\
\hline Taylor $(1996)$ & & & * & * & & & & & & & & & & & & & & & & \\
\hline Hassan (1997) & & & + & + & + & - & + & & 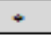 & & & & & & & & & & & \\
\hline Pitt $(1997)$ & + & & & & & & & & + & + & & & & & & & & & & \\
\hline Shen et al. (1998) & - & & & & & & & - & $*$ & & - & & & & & & & & & \\
\hline Labib et al. (1998) & & $*$ & & & $*$ & & & $*$ & & & & $*$ & & & & & & & & \\
\hline Layzell and Ladbetter (1998) & & - & & & & & & & & & & & & & & & & & & \\
\hline Amiret al. (2001) & & & $*$ & & & & & & & & & - & & & & & & & & \\
\hline Shohet et al. $(2002)$ & * & $*$ & & & & & & & & & & & & & & & & & & \\
\hline Hasanain et al. (2003) & & & & & & & & & & & & &. & & & & & & & \\
\hline $\mathrm{Li}$ and Brown (2004) & & + & + & & & & & - & & & & & & & & & & & & \\
\hline Oke and Ayomoh (2005) & + & & & + & + & & & & & & & & & & & & & & & \\
\hline $\begin{array}{l}\text { Bertolini and Bevilacquas } \\
(2006)\end{array}$ & &  & $*$ & & & & & - & & & & &. & - & 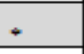 & & & & & \\
\hline Camero (2006) & & + & + & & + & + & & & + & & & & & & & & & & & \\
\hline Dann et al. (2006) & * & & & & & $*$ & & & & & & & & $*$ & & & $*$ & $*$ & & \\
\hline Frangopol and Liu (2007) & $*$ & & & & & $*$ & & & & & & & & & & & & & & \\
\hline $\begin{array}{l}\text { Jim and Peter (2007) } \\
\text { Chandrashelkaran and }\end{array}$ & + & + & & & & + & & & & & & & & 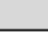 & & + & & & & \\
\hline $\begin{array}{l}\text { Chandrashelsaran and } \\
\text { Gopalalsrishnan (2008) }\end{array}$ & & & + & & & + & & + & & & & & & & & & & & & \\
\hline Gionata (2009) & & $*$ & & & & & & & & & & & & & & + & & & & \\
\hline Ali (2009) & $*$ & & & & & + & & & & & & & & + & & & & $*$ & + & \\
\hline Flores-Colen et al. (2010) & * & & * & & & & & & $*$ & * & * & & 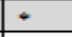 & & & & & & & \\
\hline $\begin{array}{l}\text { Vijay Kumar and Chaturvedi } \\
\text { (2011) }\end{array}$ & & * & & & & & & & & & & & & & & & & & & \\
\hline Sadeghi and Manesh (2012) & & & & & & $*$ & & & & & & - & & & - & & & & & \\
\hline Siew-Hong et al. (2014) & & * & & & & & & & & & & & & & & & & & & \\
\hline Ali and Hegagy (2014) & 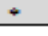 &  & & & & & & & & & & & & & & & & & & $*$ \\
\hline
\end{tabular}

though at times there might be conflicting interest among the stakeholder [32].

The case studies recorded a total of 57. There are 16 categories recorded as shown in Figure 5. Plant has the most recorded case studies. Type of plants range from aluminium, electric, oil refinery, chemical and steel plant. It is followed by manufacturing, building, and education which recorded 6 case studies respectively. Buildings include a combination of intelligent, green and normal buildings. Manufacturing covers food industry, semiconductor, and steel. Education includes both school and university.

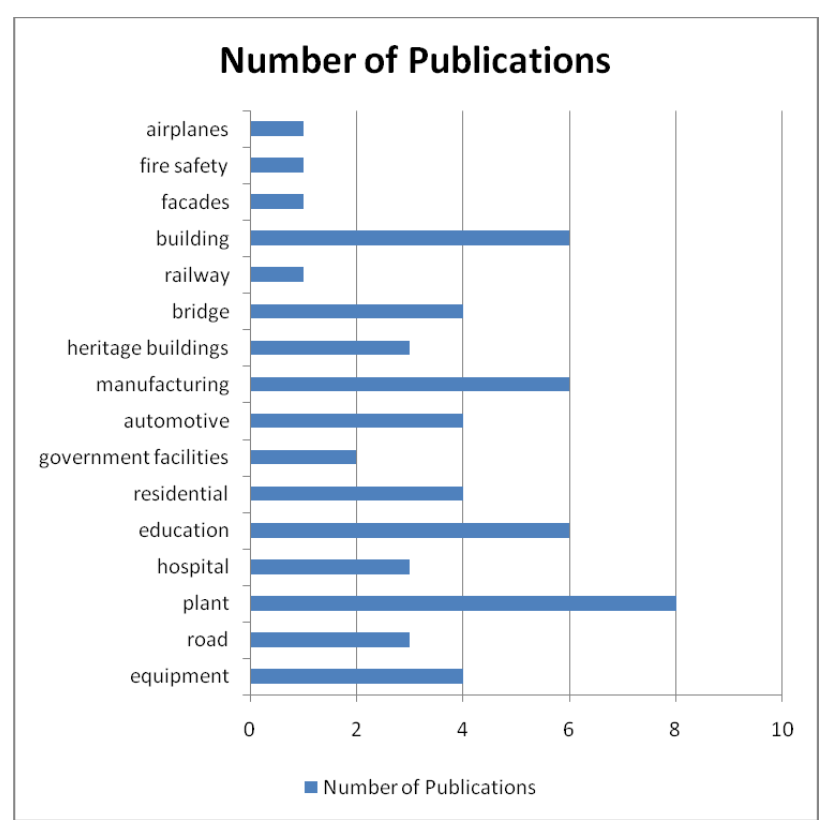

Figure 5. Types of assets in maintenance priority case studies

\section{Discussion}

Based on further content analysis of these articles, there are two relevant themes to maintenance priority. These themes are possible future research areas.

\subsection{Goal-orientated maintenance priority}

Maintenance priority starts from the top level of management which is formed by organization vision, mission, goal and objectives as shown in Figure 6 . Organizational goal is the focus of different stakeholders and constituents toward achieving a set of goals that are believe to advance the organization [15]. It is common for departments within the same organization to have conflicting interest in regards to maintenance [17]. The purpose of an organization's objective is to ensure the alignment of departmental efforts with the needs of the organization [17]. More than often problems occur when management fails to set goals at the highest level and making sure it is passed down correctly to the lower levels. [33] found that that goals are sometimes negotiated rather than based on stakeholder requirements and strategies. In a study by [32], public agencies faced difficulties in setting infrastructure objectives that aligns with the strategic policy goals. This is due to the infrastructure assets serve multiple interests of different stakeholders. [34] found that objectives and goals in asset management are lacking in Norwegian municipalities. They also lack the direction and knowledge to catch up with maintenance backlog. 


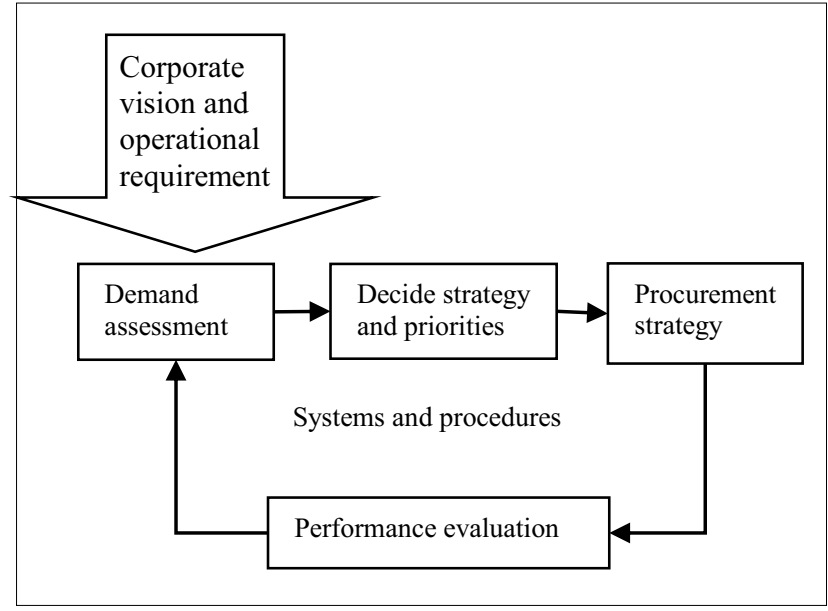

Figure 6. Asset management and maintenance [35]

Conflict is in the nature of business and can be seen in the organization structure. Senior management strives to meet both performance goal and at the same time wants the workforce to feel rewards for its efforts. As such, priority management is used to balance the needs of all party. Maintenance work order priority would have some impact on overall maintenance performance[36]. Maintenance performance could be affected as the consequences of lacking clarity in goals and objective for asset management. Performance measures that are aligned with clear policy goals and objectives help to direct resources to where they are needed to accomplish the agency's mission and can increase outcomes achieved with given levels of resources. Without clear objectives, employees relied on their personal experiences and knowledge in deciding maintenance actions [32]. This would lead to the employees to make decisions based on their personal beliefs and causes the prioritization to be more implicitly assumed than explicitly determined. Defining infrastructure objectives is important because it provides the rationale for evaluation of infrastructure condition and performance, and the prioritization of maintenance repair and renovation activities [32]. In [37], the commonly used objectives in maintenance planning are:

1. Minimizing maintenance cost

2. Maximizing asset performance

3. Minimizing risk of failure

In this context, the following research questions are relevant.

1. How do organization goal and objectives assist in maintenance priority setting?

2. How to effectively prioritize maintenance among conflicting needs?

3. What is the relationship between organization goal, maintenance priority and performance?

\subsection{Balancing maintenance priority}

From the results, different case studies would prioritize maintenance to suit their own needs. Production based maintenance would focus more on the effectiveness and efficiency of production while building based maintenance focuses on building condition, safety, aesthetics, and user satisfaction. While safety is considered as the most important criteria by some studies [38-40], there are some exception. More than often cost and budget consideration is the first consideration of maintenance managers[41, 42]. In some cases, aesthetic is prioritized so that the building perceived value is high and offers a good perception to the public [39, 43, 44]. Maintenance is often perceived differently depending on the position of the individual [35]. Surveyors would view maintenance needs from the asset protection dimension while building users would emphasize on the working environment. Owners and building managers would be more interested in priorities related to resource allocation and long term development plans. [15] argued that individuals should determine the best solution to their specific circumstances because there is no definite answer to the best way in prioritizing available resources.

In prioritizing, several authors have state the importance of taking into consideration the needs of stakeholders. As such, user satisfaction is used in priority setting. Traditionally, maintenance prioritization is carried out without taking into account the views of tenants. This is supported by [45] which stated that maintenance manager did not discuss priorities set by the client or end-users. [46] stated that tenant participant is crucial in the priority setting process as to enhance tenant's satisfaction with maintenance system. While the satisfaction of user needs to be taken into consideration, caution has to be applied as they do not possess the required maintenance knowledge to make the proper prioritization choices [14]. In a case to prioritize equipments in a hospital, maintenance managers rated medical equipment as the top priority while users rated for the washing machine [47]. A comparison must be carried out between the priorities of different stakeholders as to produce a more effective maintenance plan. In this context, the following research questions are relevant.

1. What are the critical maintenance priorities that should be considered?

2. How do the needs of stakeholders affect maintenance priority?

3. Should maintenance priority be set according to stakeholders' needs?

4. How to apply maintenance priority based on the needs of the circumstances?

\section{Conclusion}

The literature review has examined the issues relevant to the different aspects of maintenance priority factors and methods in various organizations. Articles published from 1990 to 2015 were classified and analyzed. Based on the findings of this study, the area of maintenance priority requires more systematic research efforts especially in the implementing approaches that includes organizational goals, stakeholder needs and inclusion of 
critical factors. Priority setting process that aligns with the need of the organization can assist in avoiding losses and improve the maintenance performance. Figure 7 presents a conceptual framework on maintenance priority which encompasses the findings of this study. The findings in this study contributes to the understanding of maintenance priority setting especially in the factors and methods used.

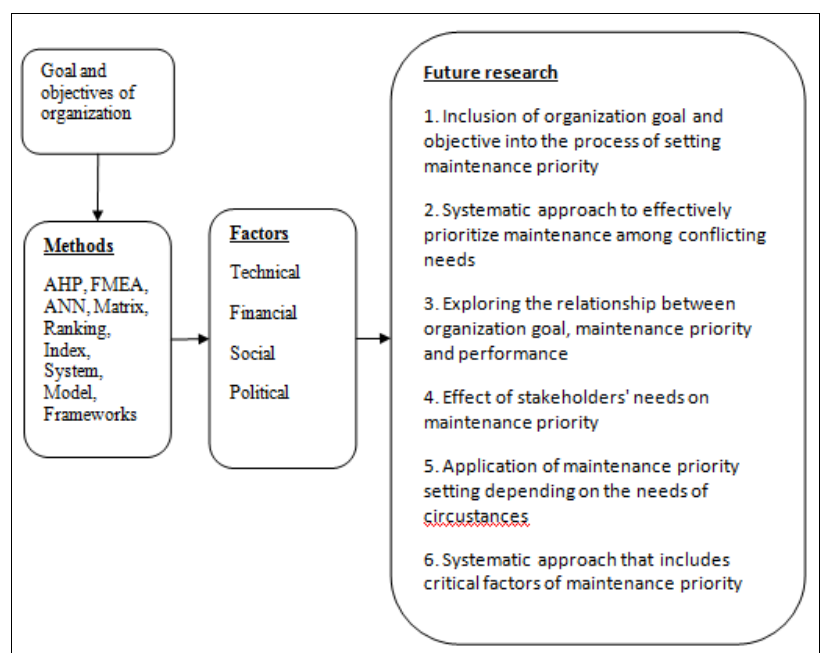

Figure 7. Gnceptual framework for setting maintenance priority

\section{References}

1. Z. A. Akasah, Shamsuddin, S. H., Rahman, I. A., Alias M., Malaysian Technical Universities Conference on Engineering and Technology (MUCEET 2009) Pahang, 1-5 (2009)

2. M. M. Idris, Constr. Manage. Econ. 16, 673-679 (1998)

3. B. Moua and J. S. Russell, J. Perform. Constr. Facil. 15, 46-53 (2001)

4. M. Y. L. T. Chew, S.S. Kang, K.H., J. Archit. Eng. 10, 80-87 (2004)

5. F. Booty, Facility management handbook. 2006, Oxford: Elsevier.

6. V. Kutut, E. K. Zavadskas, and M. Lazauskas, Arch. Civ. Mech. Eng. 14, 287-294 (2014)

7. A. O. Hopland, F. 33, 195-205 (2015)

8. W. Roy, Int. J. Oper. Prod. Man. 14, 4-24 (1994)

9. Q. Shen, F. 15, 331-339 (1997)

10. T. J. Pitt, F. 15, 97-104 (1997)

11. O. A. Lateef, J. Build. Apprais. 5, 201-212 (2009)

12. Q. Shen and A. Spedding, Build. Res. Inf. 26, 169180 (1998)

13. B. M. Kamya, Research update of a typical bridge management system applied to a UK local authority, in Bridge Maintenance, Safety, Management and Life Extension. 2014, CRC Press. p. 1757-1763.

14. N. A. Yusof, et al., Procedia - Social and Behavioral Sciences 62, 508-513 (2012)

15. S. Lavy, et al., Constr. Manage. Econ. 32, 1183-1204 (2014)

16. W. J. Moore and A. G. Starr, Comput. Ind. 57, 595606 (2006)
17. U. Kumar, et al., J. Q. M. E. 19, 233-277 (2013)

18. J. S. Mitchell, et al., Physical Asset Management Handbook. Clarion Technical Publishers(2002).

19. A. Spedding, R. Holmes, and Q. Shen. Prioritising planned maintenance in county authorities. in International Conference on Planned Maintenance, Reliability and Quality Assurance, Cambridge, UK.(1995)

20. A. Shah Ali, J. F. M. 7, 298-306 (2009)

21. Q. Shen, K.-K. Lo, and Q. Wang, Constr. Manage. Econ. 16, 693-702 (1998)

22. J. H. K. Lai, Constr. Manage. Econ. 28, 415-427 (2010)

23. A. Ali and T. Hegazy, J. Perform. Constr. Facil. 28, 528-538 (2014)

24. I. Flores-Colen and J. de Brito, Constr. Build. Mater. 24, 1718-1729 (2010)

25. J. W. Rogers, F. 31, 56-67 (2013)

26. F. Taillandier, G. Sauce, and R. Bonetto, E. C. A. M. 18, 343-362 (2011)

27. S. Antti and D. Mats, J. Q. M. E. 17, 63-73 (2011)

28. I. Flores-Colen, J. de Brito, and V. Freitas, J. Perform. Constr. Facil. 24, 337-344 (2010)

29. M. B. Hastak, E., J. Infrastruct. Syst. 7, 67-76 (2001)

30. A. A. L. Olanrewaju, B. E. P. A. M. 2, 167-181 (2012)

31. B. Hakim, C. Pierre-Jean, and Z. Nacer Eddine, J. o. S. I. T. 14, 264-280 (2012)

32. D. Schraven, A. Hartmann, and G. Dewulf, B. E. P. A. M. 1, 61-74 (2011)

33. M. Bourne, et al., I. J. B. P. M. 5, 1-24 (2003)

34. M. S. Valen and N. O. E. Olsson, J. F. M. 10, 287300 (2012)

35. T. Danny Shiem-Shin, F. 14, 12-15 (1996)

36. Q. Chang, et al., J. Manuf. Sci. E. 129, 661-668 (2007)

37. M. Hassanain, T. Froese, and D. Vanier, J. Perform. Constr. Facil. 17, 51-64 (2003)

38. N. Leveson, Reliab. Eng. Syst. Saf. 136, 17-34 (2015)

39. J. Smith and P. Stewart, S. S. 25, 24-38 (2007)

40. A. Sadeghi and R. A. Manesh, Procedia - Social and Behavioral Sciences 62, 1378-1383 (2012)

41. M. A. Amir, K. P. Andrew, and G. C. Keith, F. 19, 215-222 (2001)

42. M. Bertolini and M. Bevilacqua, Reliab. Eng. Syst. Saf. 91, 839-848 (2006)

43. N. Dann, S. Hills, and D. Worthing, Constr. Manage. Econ. 24, 97-104 (2006)

44. G. Carmignani, Reliab. Eng. Syst. Saf. 94, 861-871 (2009)

45. M. Nik Elyna, K. Syahrul Nizam, and P. Michael, J. F. M. 9, 181-199 (2011)

46. N. Ming Yip, P. M. 19, 10-18 (2001)

47. H. Al-Zubaidi, P. M. 15, 173-183 (1997)

48. R. W. Taylor,Omega 24, 217-227 (1996)

49. A. W. Labib, G. B. Williams, and R. F. O'Connor, J. Oper. Res. Soc. 49, 745-757 (1998)

50. J. Layzell and S. Ledbetter, Build. Res. Inf. 26, 351357 (1998)

51. I. M. Shohet, M. Puterman, and E. Gilboa,Constr. Manage. Econ. 20, 305-314 (2002) 
52. L. Fangxing and R. E. Brown, IEEE Trans. Power Del. on 19, 439-441 (2004)

53. S. A. Oke and M. K. O. Ayomoh, Int. J. Qual. Reliab. Manag. 22, 607-625 (2005)

54. M. Carnero, Reliab. Eng. Syst. Saf. 91, 945-963 (2006)

55. D. M. Frangopol and M. Liu, Struct. Infrastruct. E. 3, 29-41 (2007)

56. A. Chandrashekaran and B. Gopalakrishnan, J. F. M. 6, 52-68 (2008)

57. G. Carmignani, Reliab. Eng. Syst. Saf. 94, 861-871 (2009)

58. E. Vijay Kumar and S. K. Chaturvedi, Int. J. Qual. Reliab. Manag. 28, 109-126 (2011)

59. D. Siew-Hong, K. Shahrul, and A. Ishak Abdul, J. M. T. M. 25, 415-435 (2014) 